\title{
EFEITO DA COMPOSIÇÃO QUÍMICA E TEMPERATURA DE AUSTENITIZAÇÃO SOBRE A TEMPERABILIDADE JOMINY DE AÇOS BAIXO CARBONO*
}

Milena Kellen Oliveira Mendes ${ }^{1}$ Geraldo Lúcio de Faria ${ }^{2}$

\section{Resumo}

Pedro Henrique da Costa Maciel $^{3}$

O entendimento mais aprofundado dos parâmetros que afetam a temperabilidade dos aços carbono permitiu atingir propriedades antes alcançadas apenas por aços microligados. Assim, este trabalho teve como objetivo avaliar o efeito dos teores de C e Mn, assim como da temperatura de austenitização sobre a temperabilidade de aços baixo carbono, possíveis candidatos para aplicação na fabricação de vergalhões de grau 50. Três aços com composições químicas diferentes foram submetidos a ensaios de temperabilidade Jominy, considerando temperaturas de austenitização de $850^{\circ} \mathrm{C}, 920^{\circ} \mathrm{C}$ e $1050^{\circ} \mathrm{C}$. Curvas de dureza em função da distância Jominy foram construídas e análises microestruturais por microscopia óptica foram realizadas em toda a extensão dos corpos de prova. Os resultados obtidos mostraram que tanto o $\mathrm{C}$ quanto o $\mathrm{Mn}$ aumentam a temperabilidade dos aços. $\mathrm{O} \mathrm{Mn}$, por ser um elemento de liga estabilizador da austenita, dificulta a nucleação e crescimento de constituintes difusionais. O C mostrou ter maior influência sobre a temperabilidade, pois além de também ser um elemento gamagêneo, é responsável pelo cisalhamento da rede da austenita que resulta na formação da martensita. A temperatura de austenitização influenciou a temperabilidade dos aços estudados, porém seus efeitos devem ser estudados com maior profundidade.

Palavras-chave: Temperabilidade; Carbono; Manganês; Temperatura.

\section{EFFECTS OF CHEMICAL COMPOSITION AND AUSTENITIZING TEMPERATURE ON JOMINY HARDENABILITY OF LOW CARBON STEELS}

\section{Abstract}

The deeper understanding of the parameters that affect the carbon steel hardenability allowed to achieve properties later contemplated only by micro-alloy steels. This study aimed to evaluate the effect of $C$ and Mn contents, as well as the austenitizing temperature on the hardenability of low carbon steels, possible candidates for application in manufacturing grade 50 rebar. Three steels with different chemical compositions were submitted to Jominy hardenability tests, considering austenitizing temperatures of $850^{\circ} \mathrm{C}, 920^{\circ} \mathrm{C}$ and $1050^{\circ} \mathrm{C}$. Hardness curves in function of the Jominy distance were built and microstructural analysis, by optical microscopy, was performed on the entire length of the specimens. The results showed that both the $\mathrm{C}$ and the $\mathrm{Mn}$ increases the hardenability of steels. The $\mathrm{Mn}$, which is an element that stabilizes austenite, difficult the nucleation and the growth of diffusional phases. The $\mathrm{C}$ had the major influence on the hardenability, because besides being a gammagen element, it is also responsible for the austenite lattice shearing, resulting in the formation of martensite. The austenitizing temperature also influenced the hardenability, but its effects must be better studied.

Keywords: Hardenability; Carbon, Manganese, Temperature.

1 Graduanda, Engenharia Metalúrgica, Universidade Federal de Ouro Preto, Ouro Preto, MG, Brasil.

2 Físico, M. Sc., Dr., Professor, Depto. de Engenharia Metalúrgica, DEMET, UFOP, Ouro Preto, MG, Brasil

3 Engenheiro Metalúrgico, Mestrando em Engenharia de Materiais, UFOP, Ouro Preto, MG, Brasil. 


\section{INTRODUÇÃO}

Os aços são materiais versáteis que, dependendo de seu histórico termomecânico, podem apresentar diferentes propriedades mantendo uma mesma composição química. Uma das propriedades que caracteriza um possível critério de seleção de aços para aplicações em construção civil é a temperabilidade [1].

Temperabilidade é a susceptibilidade do aço de aumentar sua dureza quando submetido ao tratamento térmico de têmpera. Em outras palavras, é a capacidade de transformar parcial ou completamente de austenita para alguma fração de martensita em uma dada profundidade, quando resfriado em determinada condição. Vale ressaltar, porém, que aços de baixa temperabilidade, por exemplo, aços baixo carbono comuns, podem não ser cpazes de formar martensita. Por possuírem baixo teor de carbono, elemento responsável por cisalhar a rede cristalina da austenita, transformando-a em martensita, os aços baixo carbono podem formar uma estrutura bainítica, que também proporciona certo aumento da dureza, porém em menores proporções [2,3].

Uma das técnicas utilizadas para mensurar essa propriedade é o ensaio de temperabilidade Jominy, que consiste em austenitizar um corpo de prova e submeter uma de suas extremidades a um resfriamento com um jato d'água. Ao fim desse procedimento mede-se a dureza ao longo do comprimento do corpo de prova e constrói-se uma curva que a relaciona à posição da medida [2-4].

Vários fatores podem alterar a temperabilidade dos aços, principalmente aqueles relacionados à composição química, à homogeneidade da austenita e ao tamanho de grão austenítico [5]. A adição de elementos de liga, com exceção do cobalto, aumenta a temperabilidade dos aços, deslocando as curvas TTT (Tempo Temperatura - Transformação) para a direita. O tamanho de grão austenítico também pode provocar o deslocamento dessas curvas, uma vez que grãos de austenita maiores favorecem a formação da martensita, fase responsável pelo endurecimento do material. A homogeneidade da fase austenítica também pode surtir efeito sobre essa propriedade, já que a presença de pontos de heterogeneidade microestrutural podem dificultar a formação da martensita e diminuir a temperabilidade do aço [2].

Alguns elementos de liga produzem notáveis efeitos na temperabilidade dos aços. Dentre eles destaca-se o Manganês (Mn), assim como Cromo ( $\mathrm{Cr}$ ), Molibdênio (Mo), Silício (Si), Níquel (Ni) e Vanádio (V). O Mn retarda a transformação da austenita em ferrita e perlita devido à necessidade de redistribuição desses elementos de liga durante as transformações difusionais [1,2]. Calcagnotto et al., em experimento utilizando amostras de dois aços de composições que distinguiam-se apenas na porcentagem de $\mathrm{Mn}$, observaram que a presença desse elemento aumentou a temperabilidade do aço. Isso porque o Mn, que é estabilizador da austenita, diminui as temperaturas de início e fim de transformação austenítica, ou seja, possibilita a obtenção da mesma quantidade de austenita em temperaturas mais baixas. Além disso, o Mn diminui a taxa de resfriamento crítica para formação da martensita e aumenta a solubilidade do carbono na austenita, aumentando também a temperabilidade do aço [6].

O carbono, por sua vez, além de desempenhar o papel de elemento de liga, apresenta influência ainda mais relevante sobre a temperabilidade dos aços. Segundo Kandpal et al., o carbono é responsável pelo cisalhamento da rede cristalina cúbica de face centrada da austenita, transformando-a em martensita, fase que apresenta estrutura tetragonal de corpo centrado. Assim, a presença do carbono 
desloca as curvas de transformação perlítica e bainítica para a direita, dificultando a nucleação de constituintes difusionais e favorecendo a formação da martensita [2].

Outro fator determinante para a temperabilidade do aço é a temperatura de austenitização. Segundo Cota et al., o aumento da temperatura de austenitização acarreta aumento do tamanho de grão austenítico e consequente diminuição das áreas de contorno de grão disponíveis para nucleação heterogênea. Como as fases difusionais nucleiam preferencialmente nessas regiões, sua formação é desfavorecida. Sendo assim, a transformação martensítica é beneficiada, ou seja, a temperabilidade aumenta [7-9].

Neste contexto, este trabalho propõe-se a estudar os efeitos do C e do Mn na temperabilidade de aços baixa liga com potencial aplicação na fabricação de vergalhões para construção civil, utilizando-se para tal fim da metodologia Jominy e do auxílio da Microscopia Óptica (MO) para análise dos resultados.

\section{MATERIAIS E MÉTODOS}

\subsection{Materiais}

Para a realização deste trabalho amostras de barras redondas de três aços foram recebidas no Laboratório de Tratamentos Térmicos e de Microscopia Óptica (LTM) do DEMET-EM-UFOP. A Tabela 1 apresenta a composição química das três barras. Pode-se observar que se tratam de aços carbono, sendo um classificado como SAE J403 1030 e dois como SAE J403 1016, porém com diferenças no que diz respeito aos teores de $\mathrm{Mn}$.

\begin{tabular}{|c|c|c|c|c|c|c|c|c|c|c|}
\hline Amostra & Aço & C & Mn & $\mathbf{S i}$ & $\mathbf{P}$ & S & $\mathrm{Cu}$ & $\mathrm{Cr}$ & $\mathbf{N i}$ & Mo \\
\hline 1 & $\begin{array}{c}\text { SAE J403 } \\
1030\end{array}$ & 0,27 & 0,6 & 0,14 & 0,021 & 0,024 & 0,18 & 0,07 & 0,07 & 0,009 \\
\hline 2 & $\begin{array}{c}\text { SAE J403 } \\
1016\end{array}$ & 0,13 & 0,75 & 0,19 & 0,014 & 0,011 & 0,001 & 0,01 & 0,01 & 0,001 \\
\hline 3 & $\begin{array}{c}\text { SAE J403 } \\
1016\end{array}$ & 0,14 & 0,69 & 0,18 & 0,023 & 0,012 & 0,02 & 0,06 & 0,02 & 0,01 \\
\hline
\end{tabular}

\subsection{Procedimentos Experimentais}

Para a realização do ensaio de temperabilidade Jominy, de cada uma dessas barras foram usinados três corpos de prova padronizados pela norma NBR 6339 [4]. Para cada um dos aços, cada corpo de prova foi submetido a ensaios de temperabilidade Jominy com diferentes temperaturas de austenitização $\left(850^{\circ} \mathrm{C}, 920^{\circ} \mathrm{C}\right.$ e $\left.1050^{\circ} \mathrm{C}\right)$. As identificações dos corpos de prova e respectivas temperaturas de austenitização são apresentadas na Tabela 2.

Tabela 2. Códigos de Identificação e temperaturas de austenitização dos corpos de prova Jominy.

\begin{tabular}{lcc}
\hline Procedência & Identificações & Temperaturas de austenitização \\
\hline \multirow{3}{*}{ Barra redonda 1} & $\mathrm{~J} 1-850$ & $850^{\circ} \mathrm{C}$ \\
\cline { 2 - 3 } & $\mathrm{J} 1-920$ & $920^{\circ} \mathrm{C}$ \\
\cline { 2 - 3 } & $\mathrm{J} 1-1050$ & $1050^{\circ} \mathrm{C}$ \\
\hline \multirow{3}{*}{ Barra redonda 2} & $850^{\circ} \mathrm{C}$ \\
\cline { 2 - 3 } & $\mathrm{J} 2-850$ & $920^{\circ} \mathrm{C}$ \\
\cline { 2 - 3 } Barra redonda 3 & $\mathrm{J} 2-920$ & $1050^{\circ} \mathrm{C}$ \\
\cline { 2 - 3 } & $\mathrm{J} 2-1050$ & $850^{\circ} \mathrm{C}$ \\
\cline { 2 - 3 } & $\mathrm{J} 3-850$ & $920^{\circ} \mathrm{C}$ \\
\hline
\end{tabular}


Cada uma das amostras foi submetida a austenitização durante uma hora e em seguida disposta em dispositivo padrão para realização do ensaio. A peça teve uma de suas extremidades resfriada com um jato d'água durante dez minutos, tendo o resfriamento terminado ao ar calmo.

Após a realização dos ensaios, os corpos de prova foram retificados em todo o seu comprimento, a fim de se obter duas faces paralelas, a uma profundidade entre $0,5 \mathrm{e}$ $0,9 \mathrm{~mm}$. Foram realizadas medições de dureza Rockwell $A$ nas duas faces de cada um dos corpos de prova. A Figura 1 é uma figura esquemática que ilustra os pontos onde as medições de dureza foram realizadas. O equipamento utilizado foi um durômetro Wolpert, com penetrador de diamante e carga de $60 \mathrm{Kg}$. Foi calculada a dureza média entre os pontos correspondentes de cada uma das faces para construção de gráficos relacionando durezas e distâncias em relação à superfície temperada.

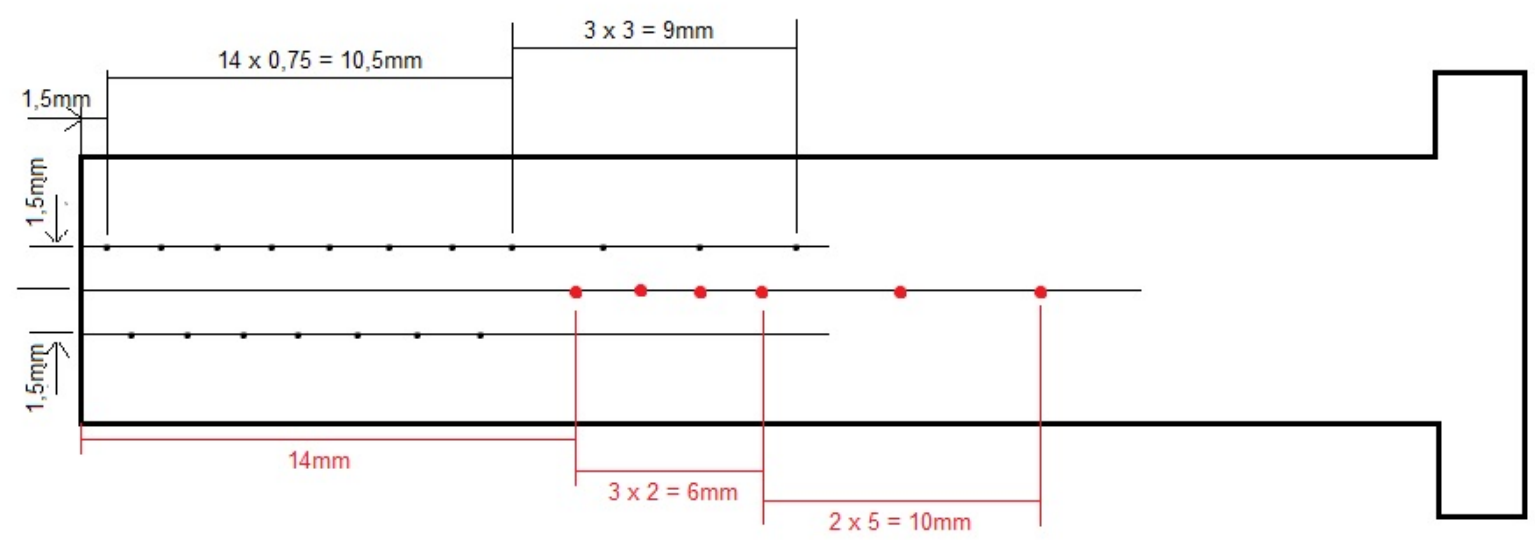

Figura 1. Representação esquemática dos pontos onde as medições de dureza foram realizadas. Em vermelho estão os pontos previstos na norma NBR 6339 [4]. Os demais pontos, em preto, foram escolhidos para melhor representar o perfil de dureza das amostras.

Findados os procedimentos relativos ao teste de temperabilidade Jominy, os corpos de prova foram metalograficamente preparados para serem submetidos a análises microestruturais. Cada corpo de prova foi lixado, polidos e atacados com Nital $4 \%$ durante alguns segundos. Com o auxílio do microscópio LEICA foram adquiridas imagens de MO para posterior análise, considerando pontos a 5, 10, 20, 30 e 60mm da superfície temperada em cada uma das amostras.

\section{RESULTADOS E DISCUSSÃO}

\subsection{Efeito do Carbono e do Manganês na Temperabilidade}

Os resultados obtidos no ensaio de temperabilidade Jominy foram dispostos em gráficos relacionando a dureza medida com a distância do ponto em relação à superfície temperada. As Figuras 2 e 3 apresentam as curvas dos três aços analisados nas temperaturas de $850^{\circ} \mathrm{C}, 920^{\circ} \mathrm{C}$ e $1050^{\circ} \mathrm{C}$, respectivamente. Neles pode-se perceber a influência da composição química na temperabilidade dos aços, especialmente os efeitos dos teores de $\mathrm{C}$ e $\mathrm{Mn}$, que são objetivos desse estudo.

Nota-se que, na Figura 2(a), considerando a temperatura de austenitização de $850^{\circ} \mathrm{C}$, a amostra $\mathrm{J} 1-850$ apresentou temperabilidade consideravelmente maior que as amostras J2-850 e J3-850, que entre si não mostraram diferenças significativas. Isto se deve à diferença no teor de $\mathrm{C}$, uma vez que a amostra J1-850 possui o dobro 
de carbono das demais. Vale ressaltar, entretanto, que a amostra J2-850, que apresenta teor de $\mathrm{Mn}$ mais alto do que a amostra J3-850, apresentou maiores valores de dureza nas proximidades da superfície temperada, revelando o efeito do $\mathrm{Mn}$ sobre a temperabilidade do aço com teor de carbono próximo de $0,15 \%$. Segundo CALCAGNOTTO et. al., esse efeito pode ser explicado pela natureza estabilizadora de austenita do Mn, que retarda as transformações difusionais e diminui as temperaturas de início e fim de transformação austenítica, assim como a taxa de resfriamento crítica para formação da martensita. $\mathrm{O} M n$ ainda atua aumentando a solubilidade do carbono na austenita, aumentando ainda mais a temperabilidade do aço $[1,2,6]$.

Na Figura 2(b), que apresenta as amostras austenitizadas a $920^{\circ} \mathrm{C}$, observa-se um perfil parecido. Destaca-se o efeito do carbono, uma vez que a temperabilidade da amostra J1-920 é muito superior em relação às demais, que não diferem muito entre si. Além disso, observa-se que as curvas das amostras J2-920 e J3-920 tiveram ligeiro decréscimo dos valores de dureza na região mais próxima ao jato d'água. Isto se deve, provavelmente, a um efeito do crescimento de grão austenítico, que em função do baixo teor de carbono destes aços, favoreceu a formação de bainita com matriz ferrítica mais bem definida e grosseira.
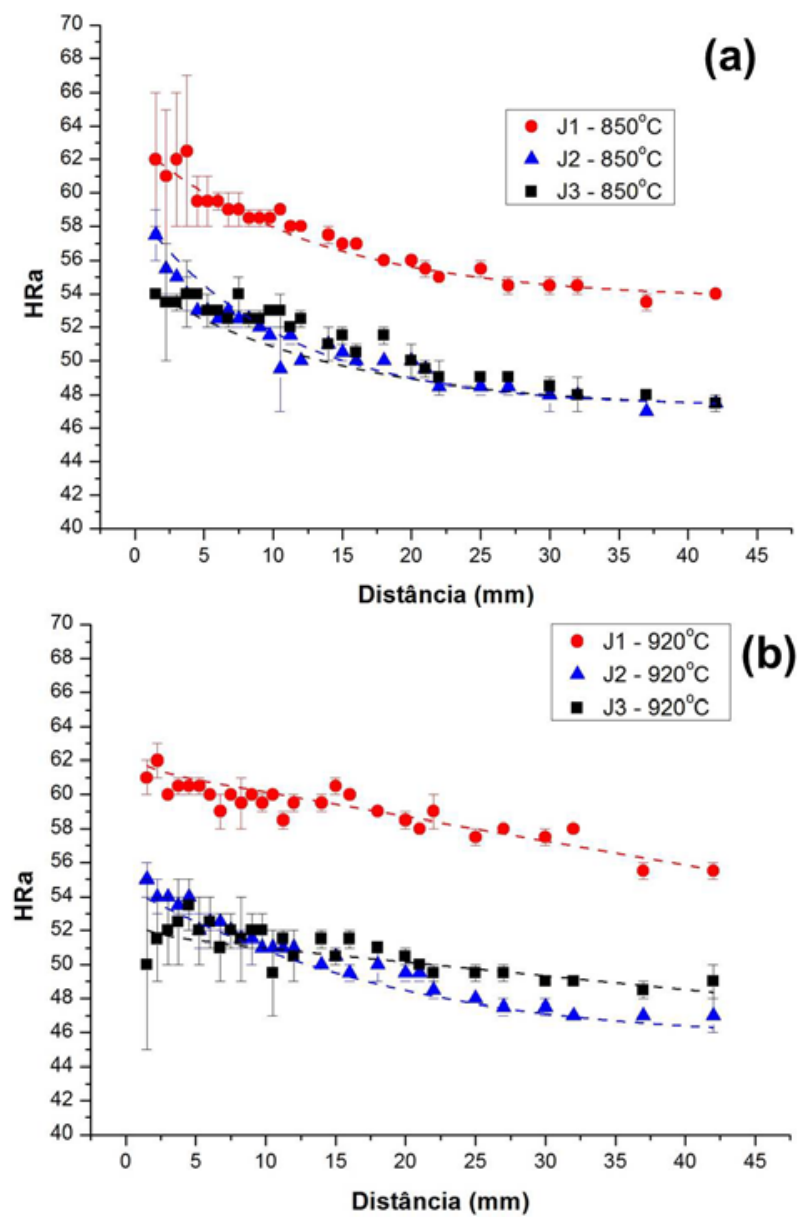

Figura 2. (a) Curvas de temperabilidade Jominy considerando temperatura de austenitização de $850^{\circ} \mathrm{C}$. (b) Curvas de temperabilidade Jominy considerando temperatura de austenitização de $920^{\circ} \mathrm{C}$.

Já na Figura 3 o efeito da composição química torna-se mais pronunciado. As durezas das três curvas diminuem ligeiramente para todas as amostras. As curvas J2-1050 e J3-1050 apresentam diferença tão significativa quanto a diferença entre 
elas e a curva de J1-1050. Ou seja, à temperatura de austenitização de $1050^{\circ} \mathrm{C}$, o efeito da composição química, em especial do $\mathrm{C}$ e do $\mathrm{Mn}$, torna-se mais evidente.

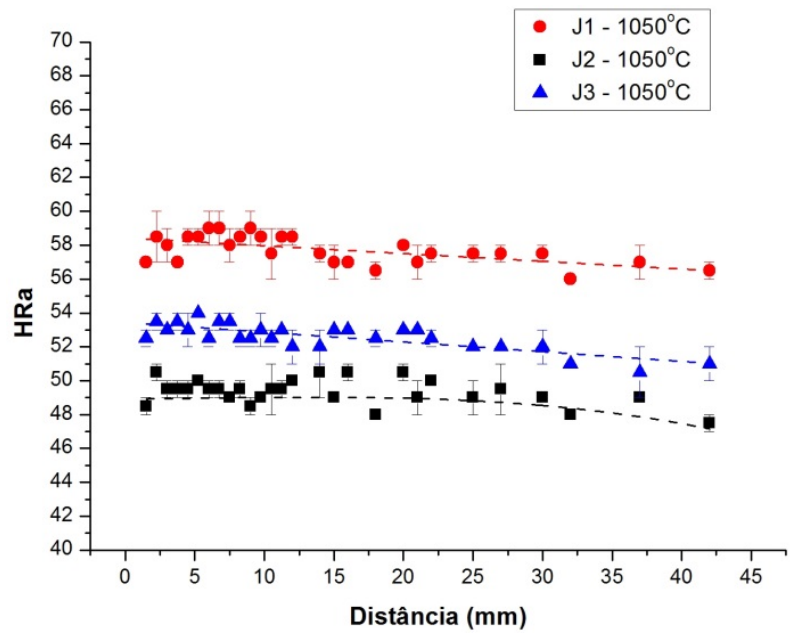

Figura 3.Curvas de temperabilidade Jominy considerando temperatura de austenitização de $1050^{\circ} \mathrm{C}$.

De um modo geral, as Figuras 2 e 3 demonstram que os teores de $\mathrm{C}$ e de $\mathrm{Mn}$ exercem forte influência na temperabilidade dos aços baixo e médio carbono, sendo o efeito do $\mathrm{Mn}$, nos teores estudados neste trabalho, menos pronunciado. Isso porque o $\mathrm{C}$, além de ser um elemento de liga, é o responsável pelo cisalhamento da rede cristalina da austenita durante a transformação martensítica, deslocando as curvas de transformação perlítica e bainítica para a direita [2]. Observa-se também que o aumento da temperatura de austenitização provocou certa tendência à linearização das curvas de temperabilidade Jominy, tornando também mais evidente o efeito da composição química nessa propriedade.

Considerando ainda o efeito da temperatura de austenitização sobre a temperabilidade dos aços estudados, as Figuras 4 e 5 apresentam as curvas de cada um dos três aços analisados nas três temperaturas consideradas $\left(850^{\circ} \mathrm{C}\right.$, $920^{\circ} \mathrm{C}$ e $1050^{\circ} \mathrm{C}$ ). Na Figura $4(\mathrm{a})$, nota-se que o efeito da temperatura no aço J1 não foi significativo em relação à disparidade entre as curvas. Porém é possível observar que, à medida que a temperatura aumenta, as curvas tendem a apresentar perfis mais lineares e com menor diferença de dureza entre a extremidade temperada e a normalizada, efeitos já discutidos anteriormente.

Na Figura 4(b), percebe-se que as durezas medidas, em geral, são menores, e que o efeito da temperatura é um pouco mais evidente nas extremidades temperadas dos corpos de prova. É importante ressaltar que a amostra submetida à maior temperatura de austenitização (J2-1050) apresentou perfil de dureza mais estável em relação às outras, o que pode indicar seu efeito em relação à temperabilidade. Entretanto, os valores mais baixos de dureza na superfície temperada poderiam ser conseqüência da existência de uma estrutura bainítica mais grosseira, decorrente do baixo teor de $\mathrm{C}$ e de um maior tamanho médio de grão austenítico prévio. 

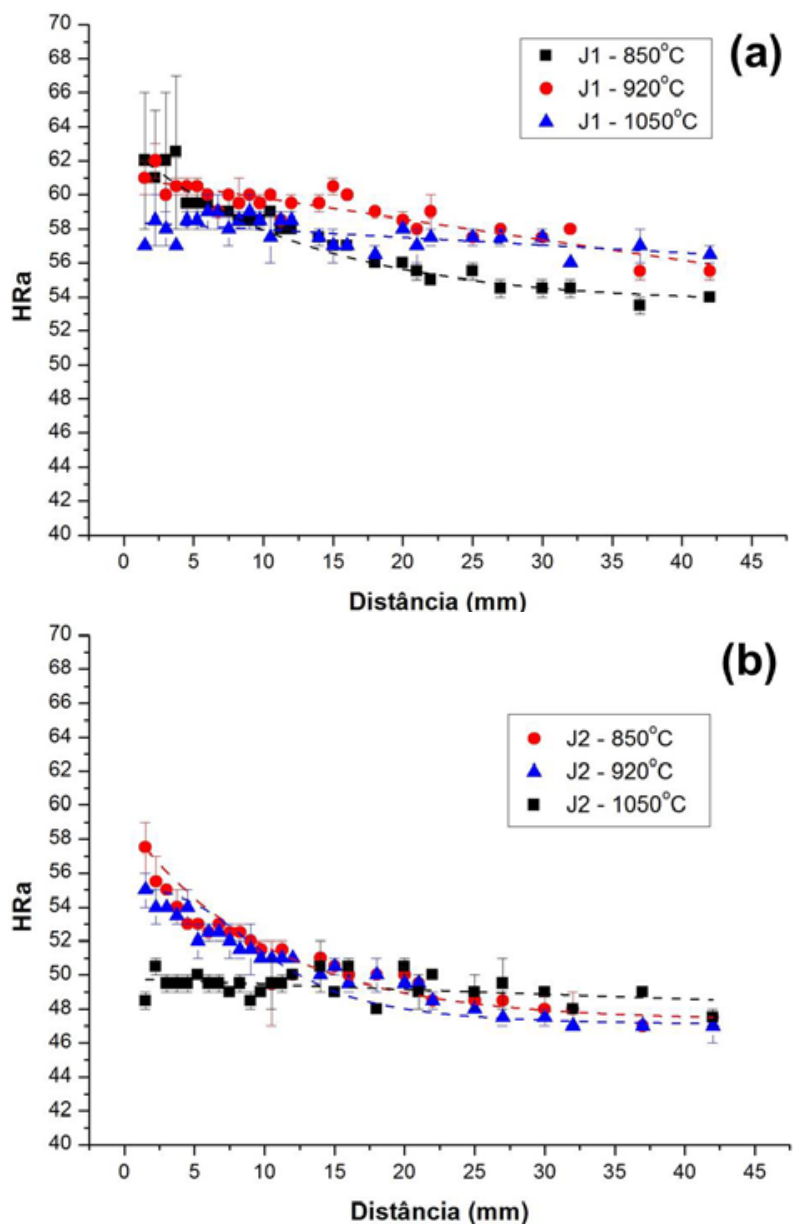

Figura 4. (a) Curvas de temperabilidade Jominy dos aços provenientes da barra redonda 1. (b) Curvas de temperabilidade Jominy dos aços provenientes da barra redonda 2.

Na Figura 5, pode-se observar que a influência da temperatura nos primeiros $10 \mathrm{~mm}$ dos corpos de prova Jominy não é significativa, porém a partir desta referência, verifica-se que quanto maior a temperatura de austenitização menor é o gradiente de dureza ao longo dos corpos de prova. Destaca-se que ao se comparar a Figura 4(b) com a Figura 5, para os primeiros $10 \mathrm{~mm}$ dos corpos de prova, verifica-se uma diferença significativa de valores absolutos de durezas que seriam justificados pelo maior teor de Mn nas amostras do grupo J2. Considerando que este estudo tem como objeto aços para fabricação de vergalhões grau 50 e que estes possuem diâmetros da ordem de $10 \mathrm{~mm}$, pode-se afirmar que uma pequena variação no teor de $\mathrm{Mn}$ pode implicar em significativas mudanças de propriedades dos vergalhões $[2,5]$. 


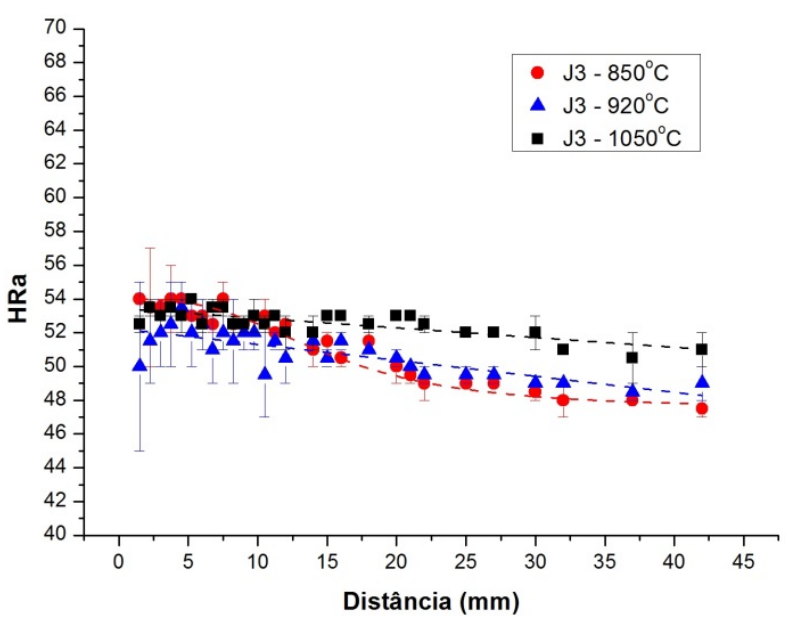

Figura 5. Curvas de temperabilidade Jominy dos aços provenientes da barra redonda 3 .

Segundo COTA et. al., o aumento da temperatura de austenitização aumenta também a temperabilidade do aço. Considerando que o aumento da temperatura de austenitização ocasiona aumento do tamanho de grão austenítico, os contornos de grão disponíveis para nucleação e crescimento heterogêneo das fases difusionais diminuirão, o que desfavorece essas transformações. Assim, o aumento da temperatura de austenitização beneficia a transformação martensítica, aumentando a temperabilidade do aço [7]. Porém, os experimentos realizados neste trabalho não permitem concluir a este respeito, visto que uma caracterização microestrutural mais detalhada se faz necessária. Pode-se supor que, para aços com baixo teor de $\mathrm{C}$, como os estudados, onde a formação de martensita mesmo em superfícies diretamente temperadas não é significativa, o aumento do tamanho de grão austenítico tenha favorecido a formação de bainita com morfologia grosseira e uma significativa fração de constituinte MA, que justificariam a diminuição da dureza com o aumento da temperatura nas extremidades temperadas.

\subsection{Análise Microestrutural}

Com o intuito de avaliar o efeito da composição química sobre a temperabilidade e sobre a microestrutura dos corpos de prova Jominy, análises microestruturais ao microscópio óptico foram realizadas a 5,20 e $60 \mathrm{~mm}$ da superfície temperada para os três aços, considerando a temperatura de austenitização de $1050^{\circ} \mathrm{C}$.

Nas Figuras 6, 7 e 8 observa-se a evolução das microestruturas das amostras J1$1050, \mathrm{~J} 2-1050$ e J3-1050, respectivamente. Em todas elas a região mais próxima à superfície temperada apresenta constituintes característicos de resfriamentos bruscos em aços baixo carbono, como a ferrita de Widmanstätten e bainita, o que só poderia ser confirmado mediante análise no Microscópio Eletrônico de Varredura (MEV).

À medida que se afasta da superfície temperada, as imagens tornam-se mais claras em função do aumento da fração de ferrita proeutetóide e da mudança gradual de morfologia de seus grãos. Na Figura 6(b), supõe-se que a ferrita coexista com uma fração significativa de bainita e perlita, assim como na Figura 6(c) a ferrita coexista com colônias de perlita fina. Nas Figuras 7 e 8, em função do baixo teor de carbono, os constituintes majoritários a $5 \mathrm{~mm}$ da extremidade temperada seriam ferrita primária e bainita. Para distâncias superiores a $10 \mathrm{~mm}$, seriam ferrita e perlita fina. 

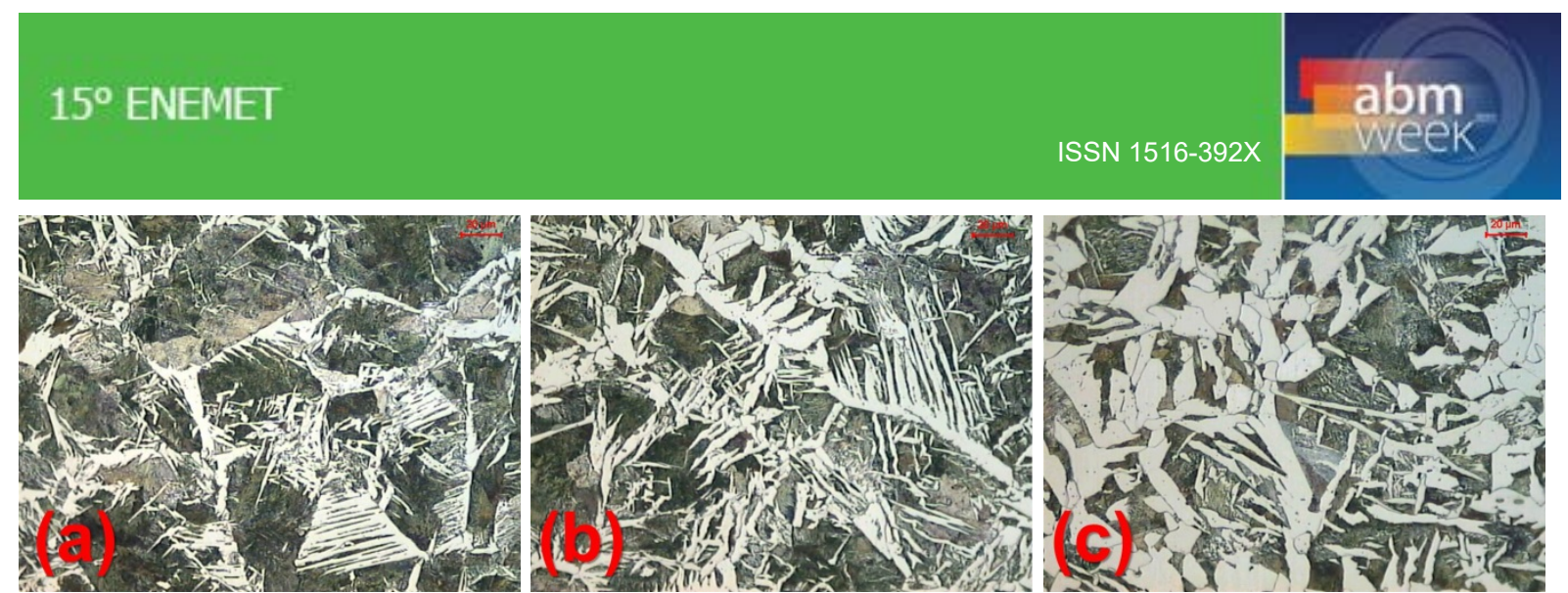

Figura 6. Microestrutura da amostra $\mathrm{J} 1-1050$ a (a) $5 \mathrm{~mm}$; (b) $20 \mathrm{~mm}$ e (c) $60 \mathrm{~mm}$ da superfície temperada. Todas as imagens com aumento de 500X.

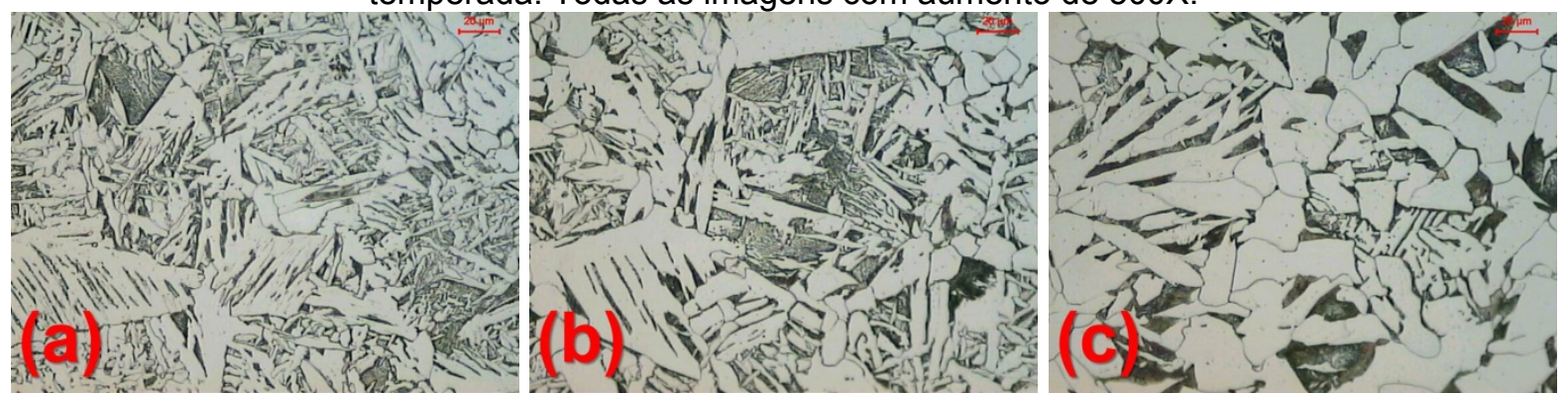

Figura 7. Microestrutura da amostra J2-1050 a (a) $5 \mathrm{~mm}$; (b) $20 \mathrm{~mm}$ e (c) $60 \mathrm{~mm}$ da superfície temperada. Todas as imagens com aumento de 500X.
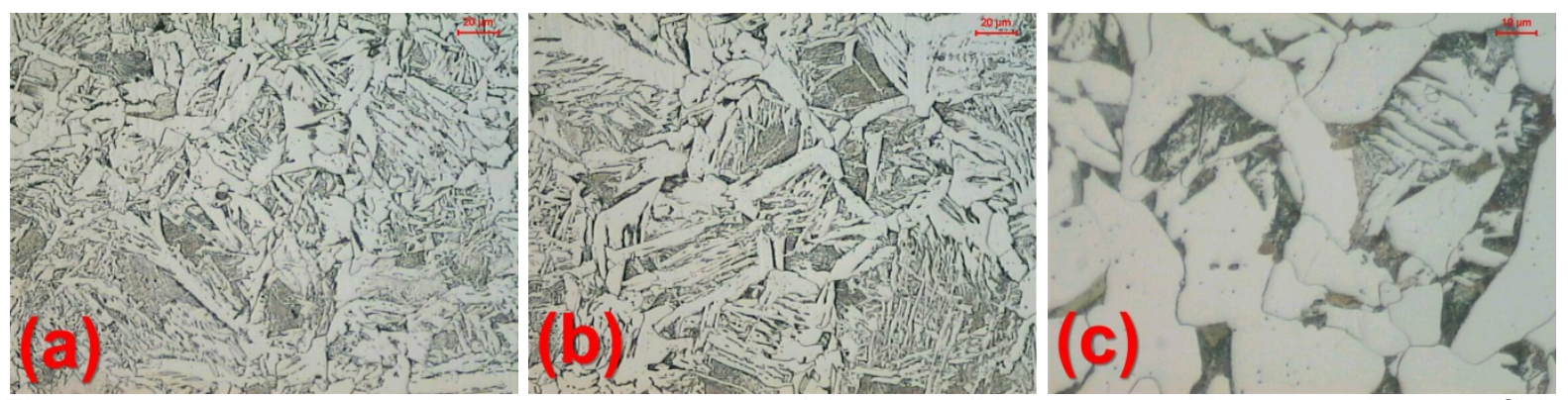

Figura 8. Microestrutura da amostra $\mathrm{J} 3-1050$ a (a) $5 \mathrm{~mm}$; (b) $20 \mathrm{~mm}$ e (c) $60 \mathrm{~mm}$ da superfície temperada. Todas as imagens com aumento de 500X.

\section{CONCLUSÕES}

Para os aços estudados, foi possível observar o efeito do Mn como elemento de liga que aumenta a temperabilidade, tendo o seu efeito pronunciado principalmente para os primeiros $10 \mathrm{~mm}$ em relação a extremidade temperada. $\mathrm{O} \mathrm{Mn}$ atuou retardando as transformações difusionais. Além disso, o Mn possibilitou o aumento da solubilidade do $C$ na austenita, potencializando o seu efeito sobre a temperabilidade.

$\mathrm{O}$ teor de $\mathrm{C}$ nos aços estudados se mostrou como fator de maior influência sobre a temperabilidade. Observou-se que quanto maior $\mathrm{O}$ teor de $\mathrm{C}$, maior a temperabilidade e as durezas das superfícies temperadas. Quanto maior o teor de carbono maior a possibilidade de se obter martensita na microestrutura temperada, ao passo que para os aços com $0,15 \%$ de $C$ houve formação mais significativa de bainita.

O aumento da temperatura de austenitização provocou tendência a uma diminuição do gradiente de dureza ao longo dos corpos de prova Jominy e ligeiro decréscimo dos valores de dureza medidos nas extremidades temperadas.

Considerando o diâmetro dos vergalhões grau 50 como sendo de aproximadamente $10 \mathrm{~mm}$, os resultados obtidos apontam a possibilidade de se utilizar aços carbono 
com teor de $\mathrm{Mn}$ ligeiramente mais alto em sua fabricação, processo que deve ser finalizado com um tratamento térmico de têmpera.

\section{Agradecimentos}

Os autores agradecem à Fundação Gorceix pelo apoio financeiro na concessão de bolsa de iniciação científica para o desenvolvimento desta pesquisa.

\section{REFERÊNCIAS}

1 Cruz LC da. Avaliação da capacidade do processo de fabricação em atender especificação de temperabilidade para o aço SAE 1548M. Dissertação de Mestrado. Junho/2005. Belo Horizonte, MG.

2 Kandpal BC, et. al. A review on Jominy Test and determination of effect of alloying elements on hardenability of steel using Jominy end quench test.

InternationalJournalofAdvances in Engineering\&Technology. 2011; volume 1: 65-71.

3 Nunes RM, et. al. ASM Handbook - Heat Treating. Ohio: American Society for Metals, 1991.

4 ABNT NBR6339/1989. Aço - Determinação da Temperabilidade (Jominy)

5 Maciel PH da C. Influência dos tratamentos térmicos de têmpera e revenimento sobre o aço SAE 1015 a fim de atender às normas do vergalhão CA50 de 10mm. Monografia de graduação. Dezembro/2013. Ouro Preto, MG.

6 Calcagnotto $\mathrm{M}$, et. al.On the effect of manganese on grain size stability and hardenability in ultrafine-grained ferrite/martensite Dual-Phase steels. Metallurgical and Materials Transactions A. 2012;volume 43:37-46.

7 Cota $A B$, et. al. Influência da temperatura de austenitização sobre a cinética de formação da ferrita em um aço microligado com Nb. Revista Escola de Minas. 2002; volume 55: 273-277.

8 Heinze C, et al. Dependency of martensite start temperature on prior austenite grainsize and its influence on welding-induced residual stresses. Computational Materials Science. 2013; volume 69: 251-260.

9 Puskar JD, et al. Effects of Varying Austenitizing Temperatures on Vacuum Hardening of Type 440C Stainless Steel. Heat Treating: Proceedings of the 25th Conference (ASM International). 2009; volume 8: 143 - 150 